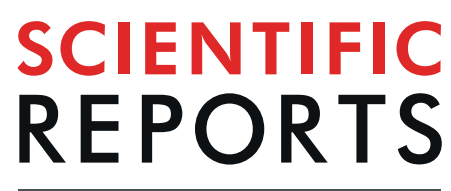

natureresearch

Check for updates

\title{
Temperate insects with narrow seasonal activity periods can be as vulnerable to climate change as tropical insect species
}

\author{
Frank Johansson ${ }^{1 凶}$, Germán Orizaola $^{1,2,3}$ \& Viktor Nilsson-Örtman ${ }^{4}$
}

The magnitude and ecological impact of climate change varies with latitude. Several recent models have shown that tropical ectotherms face the greatest risk from warming because they currently experience temperatures much closer to their physiological optimum than temperate taxa. Even a small increase in temperature may thus result in steep fitness declines in tropical species but increased fitness in temperate species. This prediction, however, is based on a model that does not account for latitudinal differences in activity periods. Temperate species in particular may often experience considerably higher temperatures than expected during the active season. Here, we integrate data on insect warming tolerance and temperature-dependent development to re-evaluate latitudinal trends in thermal safety margins after accounting for latitudinal trends in insect seasonal activity. Our analyses suggest that temperate and tropical species differ far less in thermal safety margins than commonly assumed, and add to the recent number of studies suggesting that tropical and temperate species might face similar levels of threat from climate change.

Climate change is expected to have a severe impact on the earth's biodiversity and ecosystems ${ }^{1}$. In fact, numerous studies have documented pronounced shifts in the phenology, physiology and distribution of plant and animal species associated with recent changes in climatic conditions ${ }^{2-7}$. As a consequence, there is an urgent need to develop methods that can predict the impact of future climate change on populations and species at a global scale. Ideally, these methods should be able to identify broad geographic or taxonomic trends in the susceptibility of organisms to climate change, thereby helping to guide efforts to alleviate the consequences of climate change warming more effectively ${ }^{3,8}$. While considerable progress has been made toward developing such a framework ${ }^{9-12}$, many challenges remain.

In this emerging framework, thermal performance curves (TPCs) have become a key component (Fig. 1). TPCs describe how temperature affects an organisms' fitness or key contributing functions, such as locomotion, growth and reproduction ${ }^{12,13}$. TPCs are especially relevant for ectotherms - the most diverse and widespread group of terrestrial animals - because ambient temperature has a direct and profound impact on nearly all aspects of ectotherm performance. TPCs for ectotherm performance and fitness typically show a gradual increase in performance from a critical thermal minimum $\left(\mathrm{T}_{\min }\right)$ where performance or fitness is zero, until reaching an optimal temperature $\left(\mathrm{T}_{\mathrm{opt}}\right)$ where performance is highest, before decreasing rapidly towards a critical thermal maximum $\left(\mathrm{T}_{\max }\right)$ (Fig. 1).

In the last decade several studies have synthesized and analyzed ectotherm TPC data on a global scale. Most strikingly, these studies have brought widespread attention to the fact that tropical species appear to be more vulnerable to climate change than temperate species. For example, in a seminal paper, Deutsch et al. ${ }^{11}$ used TPCs for insect fitness to estimate two measures of an organism's susceptibility to warming: the amount of warming that an organism can tolerate before it experiences a decline in fitness (thermal safety margin: TSM) or reach zero fitness (warming tolerance: WT). The results revealed that tropical species have considerably narrower thermal safety

${ }^{1}$ Uppsala University, Animal Ecology, Department of Ecology and Genetics, Evolutionary Biology Center, Norbyvägen 18D, S-75236, Uppsala, Sweden. ${ }^{2}$ IMIB-Biodiversity Research Institute (Univ. Oviedo-CSIC-Princ. Asturias), c/ Gonzalo Gutiérrez Quirós s/n, 33600, Mieres-Asturias, Spain. ${ }^{3}$ University of Oviedo, Zoology Unit, Dept Biology of Organisms and Systems, c/Rodrigo Uría s/n, 33071, Oviedo-Asturias, Spain. ${ }^{4}$ Lund University, Department

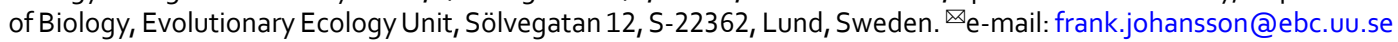



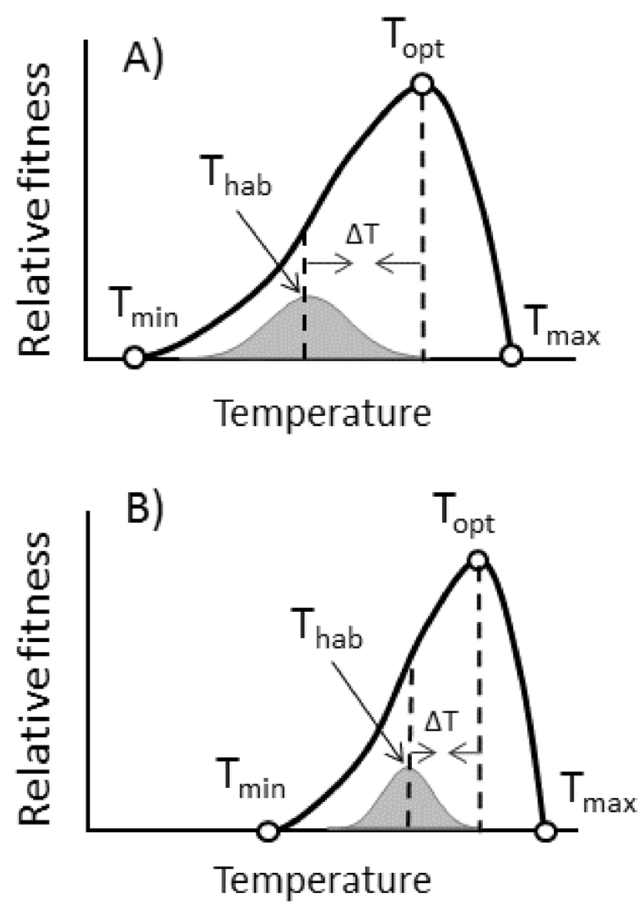

Figure 1. Thermal performance curves of ectotherms, here depicted as relative fitness. $(\mathbf{A}, \mathbf{B})$ represent a temperate and a tropical species, respectively. $\mathrm{T}_{\min }$ and $\mathrm{T}_{\max }$ represent the minimum and maximum temperature at which organisms can perform, and $\mathrm{T}_{\mathrm{opt}}$ is the optimal temperature for performance. The grey curve beneath the thermal performance curve is the temperature that the organism is exposed to during an average year and the average is depicted as $\mathrm{T}_{\text {hab }} . \Delta \mathrm{T}$ is the distance between $\mathrm{T}_{\text {hab }}$ and $\mathrm{T}_{\mathrm{opt}}$. With climate change this distance decreases and might even be shifted to the right of $\mathrm{T}_{\mathrm{opt}}$ or $\mathrm{T}_{\max }{ }^{11}$. Tropical species are assumed to be temperature specialists (B), because they have narrower thermal performance curves and, therefore, are predicted to be more sensitive to climate change ${ }^{11}$.

margins and warming tolerances than temperate species ${ }^{11}$. This suggests that even a small increase in global mean temperatures will result in precipitous declines in the fitness and performance of tropical species - as they become pushed toward or beyond their thermal maxima - whereas temperate species will benefit from an increase in mean temperatures, as they currently experience temperatures well below their thermal optimum ${ }^{14-16}$ ). Later studies, employing a similar methodology, have broadly supported these conclusions $s^{4,17-21}$.

However, more recent studies have found that mid latitude species might be the most vulnerable ${ }^{21-25}$. Using a thermal safety margin index Kingsolver et al. ${ }^{21}$ predicted that a great proportion of mid-latitude insect species would experience declines in fitness due to climate change. Similarly, Pinsky et al. ${ }^{25}$ showed that mid latitude terrestrial ectotherms, had the lowest thermal safety margin across a latitudinal gradient covering temperate and tropical species. In contrast, and in support of past studies, they found that the marine ectotherms at the equator had the lowest thermal safety margins ${ }^{25}$. Focusing on intraspecific plastic and evolved differences Diamond et al. ${ }^{23}$ concluded that the typical biogeographic pattern of high vulnerability in the tropics is exacerbated for some sources of variation while for other sources of variation, including certain types of plastic variation in heat tolerance, the biogeographic pattern of high tropical vulnerability was weak. Before a consensus can be drawn whether tropical or temperature species are more sensitive to climate change, more studies are needed. We provide one such study by reanalyzing the data set used by Deutsch et al. ${ }^{11}$. One strength of this data set is that it uses intrinsic rates of population growth (r), a direct measure of Darwinian fitness.

The prediction made by Deutsch et al. ${ }^{11}$ that tropical species are more vulnerable to warming than temperate taxa, rests on several important assumptions. Here, we examine one of these assumptions, namely that the duration of the active period of insects is similar across latitudes. This assumption arises from using annual climatological data when performing these analyses. In other words, in many studies, estimates of $\mathrm{T}_{\mathrm{opt}}$ and $\mathrm{T}_{\max }$ are compared with the mean habitat temperature across the year at each location. However, because most ectotherms become inactive during the parts of the year when conditions are unfavorable ${ }^{26}$, most organisms will tend to experience warmer and less variable temperatures during the active season than expected based on annual means and variances. Deutsch et al. ${ }^{11}$ were aware of this, and complemented their original analyses (based on annual mean temperatures) with an analysis were they calculated WTs and TSMs using the mean temperature during the three warmest months of the year at each location. Overall, this did not change their conclusions regarding latitudinal trends in the susceptibility to warming. However, in these complementary analyses, temperate and tropical organisms were assumed to have identical seasonal activity patterns (and thus become inactive during a major part of the year). This contrasts with the empirical evidence, which shows clear latitudinal trends in ectotherm activity patterns $s^{26,27}$. In particular, temperate insects display a much stronger association between insect activity and 
temperature, meaning that the mismatch between the annual climate and that experienced by individuals during the active season is likely to be greatest for insects from higher latitudes. Whether restricting the analysis to the three warmest months of the year ( $a$ in $^{11}$ or the six warmest months (as in ${ }^{21}$ re-analysis of the Deutsch et al. dataset) represents a realistic approximation of the thermal environment experienced by active insects across latitude remains unknown. Taking the biologically active period of insects and other ectotherms into consideration could thus be critical for generating more precise and biologically relevant predictions for the effects of climate change across latitudes. However, to our knowledge, no study has assessed the consequences of empirically-observed latitudinal differences in activity periods on the vulnerability to warming at a global scale.

Here, we re-examine the prediction that tropical species currently experience mean habitat temperatures that are much closer to their thermal optimum and maximum than temperate species and thus are at a greater risk from warming. To do this, we revisit the dataset used by Deutsch et al. ${ }^{11}$ and test for differences between tropical and temperate species in the vulnerability to climate change, after accounting for empirically-based estimates of insect active periods across latitudes. Admittedly, our analyses - as well as those of Deutsch et al. ${ }^{11}$ - ignore several additional factors that are increasingly known to be important for ectothermic responses to climate change, including thermoregulatory behavior ${ }^{28}$, capacity for thermal acclimation ${ }^{29}$, non-linear effects of temperature variance $^{30}$, response to the duration and intensity of extreme temperature ${ }^{31}$, shifts in phenology ${ }^{27,32}$, genetic (co) variances $^{33}$ and interspecific interactions ${ }^{34}$. Nevertheless, by focusing specifically on the assumption that active periods are similar across latitudes, we explore the importance of accounting for insect activity periods when deriving predictions for the vulnerability of populations and species across latitude to future climate change.

We define the active period of each studied insect population as the months of the year at a given location when the average temperature falls above the lower thermal threshold for insect development. After establishing the active period at each location, we re-calculate warming tolerances (WT) and thermal safety margins (TSM) using both the annual mean habitat temperature $\left(\mathrm{T}_{\mathrm{hab}}\right)$ originally used by Deutsch et al. ${ }^{11}$ and a new metric described here; the annual mean habitat temperature during the active period $\mathrm{T}_{\text {habA. }}$. When we account for differences in insect activity periods across latitudes, we predict that: 1) temperate species will experience temperatures much closer to their $\mathrm{T}_{\text {opt }}$ and $\mathrm{T}_{\max }$ than previously assumed (Fig. 1);2) temperate and tropical species will thus have more similar warming tolerances and thermal safety margins than expected based on the mean annual temperature; and 3) temperate and tropical species will face a similar risk of experiencing fitness declines under future climate change scenarios.

\section{Material and methods}

We combined two global eco-physiological datasets to re-evaluate the impact of climate change on insects across latitudes: the dataset on insect thermal tolerance previously analyzed by Deutsch et al. ${ }^{11}$ and a dataset on temperature thresholds of insect development published by Dixon et al. ${ }^{35}$. Importantly for this study, the Deutsch et al. ${ }^{11}$ dataset contain estimates of $\mathrm{T}_{\mathrm{opt}}$ and $\mathrm{T}_{\max }$ derived from TPCs for insect fitness (intrinsic population growth rate) from 38 insect species globally, and the Dixon et al. ${ }^{35}$ dataset contain estimates of the minimum developmental temperature for 66 species of insects. Briefly, our analysis followed a four-step procedure. First, we defined the lower thermal threshold for insect development $\left(\mathrm{T}_{\mathrm{dmin}}\right)$ using data from Dixon et al. ${ }^{35}$. Second, we defined the active period of each insect population in the Deutsch et al. ${ }^{11}$ dataset as the months of the year when the mean habitat temperature fell above $\mathrm{T}_{\mathrm{dmin}}$. Third, we calculated a novel metric, $\mathrm{T}_{\text {habA, }}$ which we defined as the mean habitat temperature during the active period for each population in the Deutsch et al. ${ }^{11}$ dataset. Finally, we re-calculated the warming tolerance $\mathrm{WT}$ as $\mathrm{T}_{\max }-\mathrm{T}_{\text {habA }}$ and the thermal safety margin $\mathrm{TSM}$ as $\mathrm{T}_{\text {opt }}-\mathrm{T}_{\text {habA }}$ for each population and plotted these metrics against latitude. We describe the analysis in greater detail next.

Minimum developmental temperature $\left(T_{d m i n}\right)$. Insects cannot develop below a certain temperature ${ }^{35}$. Therefore, the majority of insects at high latitudes are only active during the warmer months in a year and enter diapause at some point near the end of the growth season ${ }^{26,36}$. However, the start and end of the active season is usually not determined by temperature directly. Instead, diapause is most often triggered by photoperiodic cues, as photoperiod tends to be a much more reliable cue of long-term mean climatic conditions - and hence expected future conditions - than the current temperature alone ${ }^{26,36}$. We therefore expect photoperiodic responses to have evolved so that organisms enter diapause at the time of the year when the long-term mean temperature falls at, or slightly above, the lower developmental threshold.

Based on this, we used the months when the mean temperature lies above the lower developmental threshold temperature for insects $\left(\mathrm{T}_{\mathrm{dmin}}\right.$ ) as a biologically plausible estimate of the active period of a population. Doing so ensures that shorter periods of cold temperatures that occur within the active period will count toward the thermal conditions experienced by active insects, whereas warmer periods that occur outside these months will not (because an individual will then be in diapause).

In a review, including 66 species in 8 insect orders, Dixon et al.$^{35}$ reported a mean $\mathrm{T}_{\mathrm{dmin}}$ of $13.3^{\circ} \mathrm{C}$ across all insects. Analyzing data from the original studies, we explored whether $\mathrm{T}_{\mathrm{dmin}}$ changed systematically with latitude. We were able to retrieve data on the latitude of collection for 36 of the species in Dixon et al. ${ }^{35}$ (Supporting information, Table S1). A regression analysis of these 36 species showed no significant relationship between $\mathrm{T}_{\mathrm{dmin}}$ and absolute latitude $\left(\mathrm{r}^{2}=0.07, \mathrm{P}=0.12\right)$. However, there was a tendency for high latitude species to have somewhat lower $\mathrm{T}_{\mathrm{dmin}}$ (slope $=-0.08$ ) than low latitude species. Mean and median $\mathrm{T}_{\mathrm{dmin}}$ for species collected above or below $40^{\circ} \mathrm{N}$ in this data set was 8.9 and 11.4 , respectively. Using the mean $\mathrm{T}_{\mathrm{dmin}}$ from the original data in Dixon $e t$ $a l .35$, i.e. $13.3^{\circ} \mathrm{C}$, could thus introduce a bias in that northern species would appear to be relatively more sensitive to warming. We therefore use the mid-range value between the mean and the median, $10^{\circ} \mathrm{C}$, as a conservative estimate of $\mathrm{T}_{\mathrm{dmin}}$ for all species when calculating the mean ambient temperature experienced during the active period. An alternative for the $10^{\circ} \mathrm{C}$ limit would be to use the actual threshold for all the 38 species we use, but 
unfortunately this would drop our replicate number considerable. Our mean ambient estimate is approximately the same as that used in recent studies on effects of climate change on insects, e.g. Buckley et al. ${ }^{27}$, and the number of dropped months compared to Deutsch et al. ${ }^{11}$ can be seen in Supporting information, Table S2.

Habitat temperature during the active period ( $\left.T_{\text {habA }}\right)$. Insects are ectotherms and therefore the body temperature of most species closely matches that of their habitat in the absence of behavioral thermoregulation ${ }^{37}$. Based on this, we calculated $\mathrm{T}_{\mathrm{habA}}$ as the mean air temperature of those months were the temperature was above $10^{\circ} \mathrm{C}$ for the 38 species of insects that were provided in Deutsch et al. ${ }^{11}$. We were unable to retrieve the exact same observational climatic dataset as that used by Deutsch et al. ${ }^{11}$. We therefore used a slightly different set of observational climatic data (the coordinates for the climate data set differ slightly at the collection location). To determine if our climatic dataset was comparable to that used by Deutsch et al. ${ }^{11}$, we re-calculated $\mathrm{T}_{\text {hab }}$ using our climatic dataset and compared the results with those originally presented by Deutsch et al. ${ }^{11}$. The results were highly congruent (Supporting information, Table S2).

Climate data. Monthly baseline climate data for the $20^{\text {th }}$ century (1901-2009) for each month was obtained from (https://climateknowledgeportal.worldbank.org). The data comes from the globally available observational datasets derived from the Climate Research Unit (CRU) of the University of East Anglia (http://www.cru.uea. ac.uk/data). For the future global warming we used the predicted mean monthly temperate for the year 2080 using, as in Deutsch et al. ${ }^{11}$, the simulation from the Geophysical Fluid Dynamics Laboratory model CM2.1 ${ }^{38}$ that is forced by the $\mathrm{A} 2$ greenhouse gas emissions scenario (obtained at https://climatewizard.ciat.cgiar.org) based on grid cell resolutions.

Warming tolerance (WT) and Thermal safety margin (TSM) for the active period. Following Deutsch et al. ${ }^{11}$, thermal performance was estimated as the intrinsic rate of population growth $\left(\mathrm{r}_{\max }\right)$ across a range of constant temperatures. This value is a direct estimate of Darwinian fitness, and is thus a proper fitness estimate for each species ${ }^{39} . \mathrm{T}_{\min }, \mathrm{T}_{\text {opt }}$ and $\mathrm{T}_{\max }$ for 38 species at the location of collection was obtained from the data set in Deutsch et al. ${ }^{11}$. Thereafter, we estimated warming tolerance (WT) and thermal safety margin (TSM) at the site of collection for each species using the formulas $\mathrm{WT}=\mathrm{T}_{\max }-\mathrm{T}_{\text {hab }}$, and $\mathrm{TSM}=\mathrm{T}_{\mathrm{opt}}-\mathrm{T}_{\text {hab }}$ respectively, using the predicted temperature in 2080. As stated above, we calculated the yearly habitat temperature in two ways: using a 12-month approach considering each month mean $\left(\mathrm{T}_{\text {hab }}\right.$; same as in Deutsch et al. $\left.{ }^{11}\right)$, and our new approach using only means of months where the temperature was $>10^{\circ} \mathrm{C}\left(\mathrm{T}_{\text {habA }}\right)$.

The effects of warming on insect performance was visualized by plotting WT and TSM against latitude of origin for each of the 38 species analyzed by Deutsch et al. ${ }^{11}$ for their 2080 warming scenario. We created two different plots: one for the entire year $\left(\mathrm{T}_{\text {hab }}\right)$ and one for only the active period $\left(\mathrm{T}_{\text {habA }}\right)$. In these plots we also show the predicted temperatures increase at each latitude for the year 2080. To visualize trends in WT and TSM across latitude we used a second-degree polynomial model. These graphs were done in the R package lme4.

To evaluate if tropical species were more sensitive to climate change compared to temperate species we calculated two temperature sensitivity indices (1): WT - predicted mean temperature ( $\Delta \mathrm{T}$ in Fig. 1); and (2) TSM - predicted mean temperature increase. Again, we did so using both $\mathrm{T}_{\text {hab }}$ and $\mathrm{T}_{\text {habA. }}$. We define the tropics as the area between $23.5^{\circ} \mathrm{N}$ and $23.5^{\circ} \mathrm{S}^{40}$. This gave us a total of 6 tropical species and 32 temperate species. The differences in temperature sensitivity indices between tropical and temperate species were tested with $\mathrm{t}$-tests using Minitab version 17.

\section{Results}

As originally reported by Deutsch et al. ${ }^{11}$, warming tolerances (WT) and thermal safety margins (TSM) increased steeply with latitude (Fig. 2A,B,) when we calculated these metrics using the annual mean habitat temperature $\mathrm{T}_{\text {hab }}$ as in Deutsch et al.' $\mathrm{s}^{11}$ original analysis. The pattern was significantly better described by a quadratic regression model than a linear model (WT: $\mathrm{F}_{1,35}=22.37, \mathrm{P}<0.001$; TSM: $\mathrm{F}_{1,35}=29.19, \mathrm{P}<0.001$ ). Similar to previous studies, tropical species (below $23^{\circ}$ latitude) had on average significantly narrower warming tolerances ( $\mathrm{t}$-test, $\mathrm{t}=3.62, \mathrm{P}=0.003)$ and thermal safety margins $(\mathrm{t}=2.83, \mathrm{P}=0.015)$ than temperate species (above $23^{\circ}$ latitude). Furthermore, one tropical species and one temperate species was predicted to experience mean annual temperatures that exceeded their thermal safety margin by 2080 (dots below the red line in Fig. 2B). Because the data set is heavily biased towards temperate species, this represent $17 \%$ of tropical species and $1 \%$ or temperate species being identified as at risk from warming.

In contrast, WT and TSM showed a considerably flatter latitudinal trend when we accounted for latitudinal differences in insect activity periods by calculating these metrics using the mean temperature during the active season $\mathrm{T}_{\text {habA }}$ (Fig. 2C,D,). The pattern was still significantly better described by a quadratic regression model than a linear model (WT: $\mathrm{F} 1,35=10.15, \mathrm{P}=0.003$; TSM: $\mathrm{F} 1,35=11.21, \mathrm{P}=0.002$ ). However, after accounting for activity periods, tropical and temperate species did not differ overall in either warming tolerance (Fig. 3A; $t$-test, $\mathrm{t}=1.30$, d.f. $=8.9, \mathrm{P}=0.22$ ) or thermal safety margin (Fig. $3 \mathrm{~B}$; $\mathrm{t}$-test, $\mathrm{t}=0.63$, d.f. $=7.43, \mathrm{P}=0.55$ ) based on currently available data. Moreover, one tropical species and three temperate-zone species were predicted to experience mean temperatures during the active season that exceeded their thermal safety margins by 2080 (Fig. 2D). This analysis accounting for latitudinal differences in insect active periods thus identified $17 \%$ of tropical species and $9 \%$ of temperate species as at risk to warming.

Accounting for insect activity periods had a greater impact on the predicted warming tolerances and safety margins in temperate than tropical species. Warming tolerances calculated using the mean annual temperature $\mathrm{T}_{\text {hab }}$ were significantly higher than those calculated using the mean temperature during the active season $\mathrm{T}_{\text {habA }}$ for temperate ( $\mathrm{t}$-test, $\mathrm{t}=3.00$, d.f. $=53.3, \mathrm{P}=0.004$ ) but not tropical species $(\mathrm{t}=-0.008, \mathrm{~d} . \mathrm{f}$. $=10, \mathrm{P}=0.99)$. Likewise, thermal safety margins were significantly higher when calculated using $\mathrm{T}_{\text {hab }}$ than $\mathrm{T}_{\text {habA }}$ for temperate $(\mathrm{t}=3.22$, d.f. $=53.3, \mathrm{P}=0.002)$ but not tropical species $(\mathrm{t}=-0.007$, d.f. $=10, \mathrm{P}=0.99)$. 

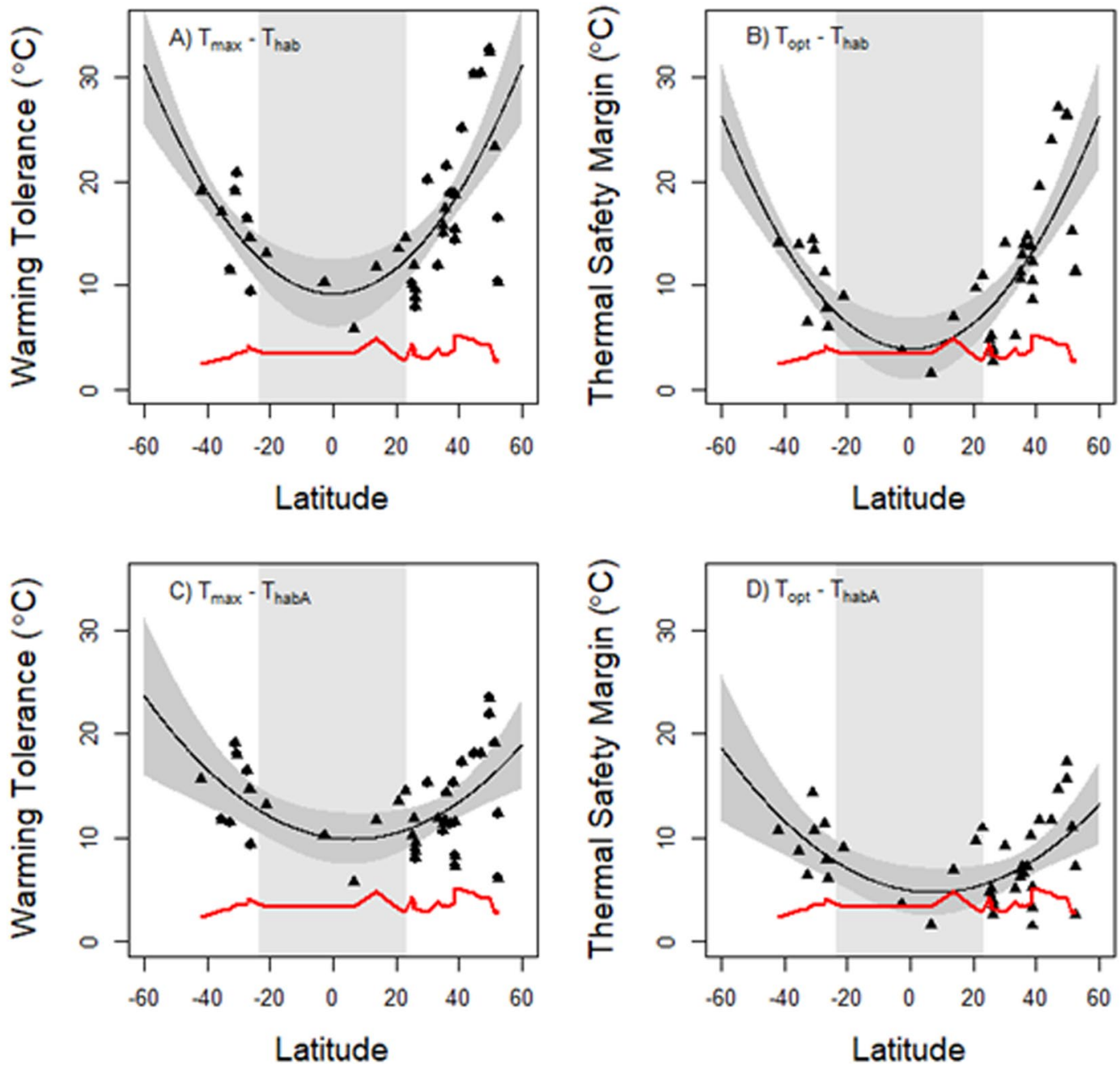

Figure 2. Warming tolerances (WT) and thermal safety margins (TSM) of insects as a function of latitude. In $(\mathbf{A}, \mathbf{B})$ warming tolerances and thermal safety margins were calculated using the mean annual temperature $\mathrm{T}_{\text {hab }}$ as in several previous studies (i.e. $\mathrm{WT}=\mathrm{T}_{\max }-\mathrm{T}_{\text {hab; }}, \mathrm{TSM}=\mathrm{T}_{\mathrm{opt}}-\mathrm{T}_{\text {hab }}$ ). In $(\mathbf{C}, \mathbf{D})$, warming tolerances and thermal safety margins were calculated using the mean temperature during the months of the year when insects are developmentally active, $\mathrm{T}_{\text {habA }}$ (i.e. $\mathrm{WT}=\mathrm{T}_{\max }-\mathrm{T}_{\text {habA; }}, \mathrm{TSM}=\mathrm{T}_{\text {opt }}-\mathrm{T}_{\text {habA }}$ ). The red line represents the predicted increase in mean temperature at each latitude by 2080. Species whose data points fall below this line in $(\mathbf{B}, \mathbf{D})$ are predicted to experience mean habitat temperature that exceed their $\mathrm{T}_{\mathrm{opt}}$ in 2080 , and thus decline in fitness. Note that species whose data points fall near the red line may also experience fitness declines under climate change due to thermal fluctuations that exceed $\mathrm{T}_{\text {opt. }}$. Tropical areas (defined here as regions located between $23^{\circ} \mathrm{N}$ and $23^{\circ} \mathrm{S}$ latitude) are shaded in light gray. Predictions from a second-degree polynomial model for the latitudinal trend in WT and TSM are shown in black; 95\% confidence intervals for the predictions are shown in dark gray.

\section{Discussion}

Our study suggests that temperate and tropical insects are more similar in their vulnerability to climate warming than expected based on several recent models. These findings support some recent studies finding that ectotherms of temperate and tropical species might differ far less in response to climate change than predicted in past studies ${ }^{21-25}$. Specifically, we find that previous analyses that have compared thermal optima and maxima $\left(\mathrm{T}_{\text {opt }}\right.$ and $\left.\mathrm{T}_{\max }\right)$ with the annual mean habitat temperature $\left(\mathrm{T}_{\text {hab }}\right)$ have greatly overestimated the warming tolerances (WT) and thermal safety margins (TSM) of temperate species (Fig. 2A,B), but not those of tropical species. When we account for differences in seasonal activity patterns across latitude, by calculating the mean temperature during the months of the year when insects are developmentally active $\mathrm{T}_{\text {habA }}$, increases in mean WTs and TSMs with latitude becomes considerably smaller in magnitude than reported in several earlier studies (Fig. 2C,D). This discrepancy simply arises because our metric $\mathrm{T}_{\text {habA }}$ is not biased downward by including very cold winter temperatures that are not experienced by developmentally active insects at higher latitudes.

Our analyses highlight the striking variability in warming tolerances and thermal safety margins in temperate species (Fig. 2C,D). This variability, together with the weak latitudinal trend in WT and TSM, does not support the generalization that tropical species are more vulnerable overall than temperate species (Fig. 3), although it 

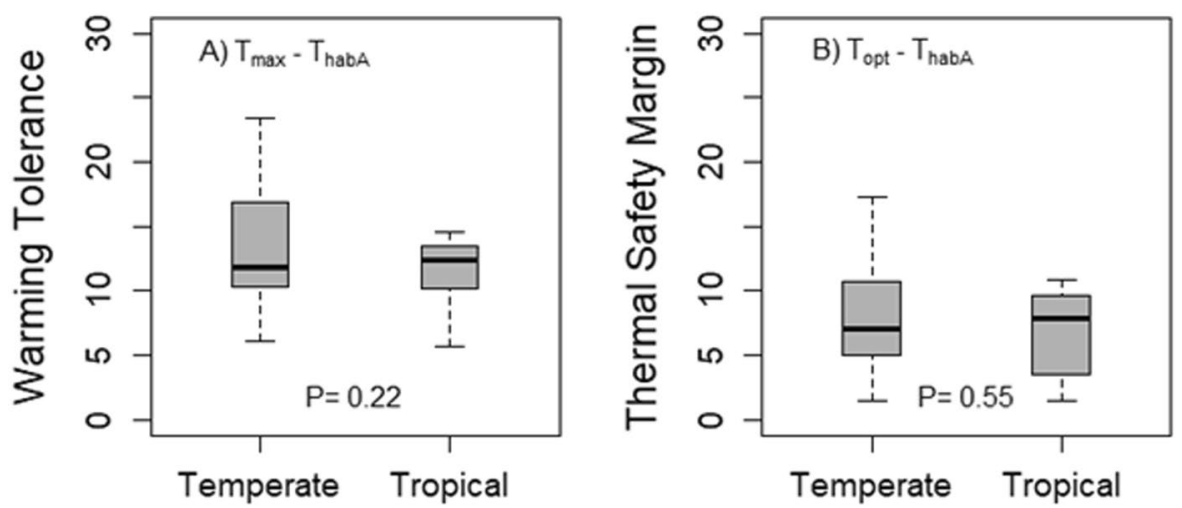

Figure 3. Difference in warming tolerance (A) and thermal safety margins (B) between temperate and tropical species when accounting for latitudinal differences in insect activity periods. Box plots show median, quartiles and range. P-values are based on t-tests. Tropical areas are defined as regions between $23^{\circ} \mathrm{N}$ and $23^{\circ} \mathrm{S}$ latitude.

should be noted that on average, TSM and WT tends to increase non-linearly with latitude here as in previous studies. The weak differences we observe between temperate and tropical taxa contrasts with the results from several earlier studies $4,11,15,17,18,20,41$ that have not accounted for activity periods.

We find the variation in TSM in the temperate zone to be so great that three temperate species - but only one tropical species - showed reduced fitness following the $5^{\circ} \mathrm{C}$ increase in average temperatures forecasted by 2080 under IPCC scenario A2 (Fig. 2D; points falling under the red line). This represents $9 \%$ and $17 \%$ of temperate and tropical species studied, respectively. These relatively similar level of risk stands in stark contrast with the predictions from Deutsch et al'. ${ }^{11}$ original analysis. While their analysis also showed large levels of variation in WT and TSM for temperate species (c.f. Fig. 2B), the mean WT and TSM was estimated to be so high for temperate species that all insects above $40^{\circ} \mathrm{N}$ were predicted to experience increased fitness even after a $10^{\circ} \mathrm{C}$ increase in temperature. Clearly, more data on both tropical and high-latitude species is needed before any firm conclusions can be drawn. Such information might be available now, about a decade later. However, the purpose of our study was simply to show that taking seasonal activity into account will change the predictions along a latitudinal gradient.

The effects of climate change will not only be felt through changes in mean temperature, but also from changes in the variance of temperature experienced over annual and diurnal time scales. In the analyses presented here, we focus on changes in mean temperature for two reasons. Firstly, it enables us to clearly isolate the magnitude of the effect of accounting for insect activity periods across latitude, and secondly, it enables us to directly compare the results from our analyses with those in the original, highly influential, study by Deutsch et. al. ${ }^{11}$ However, our findings, that temperate species face a greater risk from warming than commonly expected, reinforce those of two recent studies that have re-analyzed the Deutsch et al. ${ }^{11}$ dataset to explore the consequences of increases in both the mean and variance of temperature under climate change ${ }^{21,30}$. Both these studies found that, because mid-latitude environments experience considerably greater variance in temperature than tropical environments, insects from mid-latitudes will experience greater decline in fitness under climate change because they will encounter temperatures above $T_{\text {opt }}$ with increasing frequency ${ }^{21,30}$. However, note that this arises because temperate environments show greater variation in in temperature than tropical environments. Our results add to these findings by showing that active insects also experience these temperate environments as warmer than expected based on conditions averaged over the whole year, because temperate insects have shorter active periods. When we add the effect of thermal fluctuations (and increases in thermal variability under warming) to this, we expect that this will further exacerbate the vulnerability of the temperate species that we identify as having narrow thermal safety margins.

The study by Kingsolver et al. ${ }^{21}$ is an especially relevant comparison, as they also performed separate analyses using temperature data for both the full year and the 'growing season', which they define as May-October in the northern hemisphere (but note that their analysis did not account for differences in the length and timing of the active period across latitude, as we do here). As in our study, Kingsolver et al. ${ }^{21}$ found that a considerably greater proportion of mid-latitude species $\left(20-40^{\circ}\right.$ absolute latitude) will experience declines in fitness when we only consider the conditions they experience during the growing season. In addition, Kingsolver et al. ${ }^{21}$ also found that responses were especially heterogeneous at mid-latitudes, with some species showing increases, and some species decreases, in fitness, which is in concert with our findings. Hence, by using a somewhat different approach we found similar results as Kingsolver et al. ${ }^{21}$, and thus our study adds up to the recent suggestions that tropical and temperate species might have similar vulnerability to climate change $\mathrm{e}^{21-25}$.

Estimates of WT and TSM from TPCs for fitness $(r)$ represent a highly valuable source of data on species' vulnerabilities to warming, as they have been estimated for a relatively large number of species using a consistent methodology, and capture the overall effect of temperature on a set of complex underlying processes that are intrinsically linked to the demographic rates of populations. However, it is becoming increasingly clear that more complex models will be needed to predict the response of individual species with any certainty. Mechanistic models, tailor-made for specific organisms, are becoming increasingly sophisticated. These incorporate, for example, the effects of thermoregulatory behavior ${ }^{25}$, capacity for thermal acclimation ${ }^{29}$, response to the duration and intensity of extreme temperatures ${ }^{31}$, genetic (co)variances ${ }^{33}$ and interspecific interactions ${ }^{34,42}$. However, to apply 
such mechanistic models on a global scale will require a large amount of data that is currently not available for more than a handful of species. Therefore, we believe that TPCs for fitness will continue to serve an important role for identifying the broad trends in the vulnerability to warming. Going forward, we strongly urge researchers to consider latitudinal differences in active periods when exploring this rich source of information.

Our analysis ignores sources of selection that occurs during the non-active period. This decision may be defensible when analyzing changes in the expression of performance traits (feeding, growth, locomotion, etc) that are only expressed during this part of the year. However, because fitness represents the joint outcome of survival and reproductive success, it may be especially important to also account for mortality that occur during the non-active periods. Likewise, because TPCs for fitness are typically estimated under controlled laboratory conditions, it is important to note that published fitness estimates also ignore many other important sources of selection, including predation, competition, resource availability, etc, that occur both within and outside the active period. We also note that the information currently available on insect thermal responses is highly incomplete and biased. Large areas remain entirely unsampled (Supporting information, Fig. S4), most notably all of South America, and very few populations above $50^{\circ} \mathrm{N}$ have been studied (none above $53^{\circ} \mathrm{N}$ ). Hence, for a good understanding on how climate change will affect insect species above $50^{\circ} \mathrm{N}$ much more data on fitness estimates at different temperatures are urgently needed.

In summary, our work reveals that temperate species have considerably narrower safety margin to warming than suggested by several earlier analysis. Because temperate ectotherm species also harbor considerable variation in $\mathrm{T}_{\text {opt }}$ and $\mathrm{T}_{\max }$ (Supporting information, Table S2) it will be important to have much more data on thermal tolerance and fitness components across latitudes before we can make more precise predictions on the impacts of climate change.

Received: 28 January 2020; Accepted: 9 April 2020;

Published online: 01 June 2020

\section{References}

1. Urban, M. C. Accelerating extinction risk from climate change. Science 348, 571-573, https://doi.org/10.1126/science.aaa4984 (2015).

2. Parmesan, C. Ecological and evolutionary responses to recent climate change. Annu. Rev. Ecol. Evol. Syst. 37, 637-669, https://doi. org/10.1146/annurev.ecolsys.37.091305.110100 (2006).

3. Parmesan, C. Influences of species, latitudes and methodologies on estimates of phenological response to global warming. Glob. Change Biol. 13, 1860-1872, https://doi.org/10.1111/j.1365-2486.2007.01404.x (2007).

4. Dillon, M. E., Wang, G. \& Huey, R. B. Global metabolic impacts of recent climate warming. Nature 467, 704-706, https://doi. org/10.1038/nature09407 (2010).

5. Thackeray, S. J. et al. Phenological sensitivity to climate across taxa and trophic levels. Nature 535, 241, https://doi.org/10.1038/ nature18608 (2016).

6. Pecl, G. T. et al. Biodiversity redistribution under climate change: Impacts on ecosystems and human well-being. Science 355, eaai9214, https://doi.org/10.1126/science.aai9214 (2017).

7. Lister, B. C. \& Garcia, A. Climate-driven declines in arthropod abundance restructure a rainforest food web. Proc. Natl. Acad. Sci. 115, E10397-E10406, https://doi.org/10.1073/pnas.1722477115 (2018).

8. Root, T. L. et al. Fingerprints of global warming on wild animals and plants. Nature 421, 57, https://doi.org/10.1038/nature01333 (2003).

9. Thuiller, W. Patterns and uncertainties of species' range shifts under climate change. Glob. Change Biol. 10, 2020-2027, https://doi. org $/ 10.1111 / j .1365-2486.2004 .00859 . x(2004)$.

10. Botkin, D. B. et al. Forecasting the effects of global warming on biodiversity. AIBS Bull. 57, 227-236, https://doi.org/10.1641/ B570306 (2007).

11. Deutsch, C. A. et al. Impacts of climate warming on terrestrial ectotherms across latitude. Proc. Natl. Acad. Sci. 105, 6668-6672, https://doi.org/10.1073/pnas.0709472105 (2008).

12. Sinclair, B. J. et al. Can we predict ectotherm responses to climate change using thermal performance curves and body temperatures? Ecol. Lett. 19, 1372-1385, https://doi.org/10.1111/ele.12686 (2016).

13. Huey, R. B. \& Stevenson, R. D. Integrating Thermal Physiology and Ecology of Ectotherms: A Discussion of Approaches. Am. Zool. 19, 357-366, https://doi.org/10.1093/icb/19.1.357 (1979).

14. Addo-Bediako, A., Steven, L., Chown, S. L. \& Gaston, K. J. Thermal tolerance, climatic variability and latitude. Proc. R. Soc. Lond. Ser. B-Biol. Sci. 267, 739-745, https://doi.org/10.1098/rspb.2000.1065 (2000).

15. Compton, T. J., Rijkenberg, M. J., Drent, J. \& Piersma, T. Thermal tolerance ranges and climate variability: a comparison between bivalves from differing climates. J. Exp. Mar. Biol. Ecol 352, 200-211, https://doi.org/10.1016/j.jembe.2007.07.010 (2007).

16. Sunday, J. M., Bates, A. E. \& Dulvy, N. K. Global analysis of thermal tolerance and latitude in ectotherms. Proc. R. Soc. B Biol. Sci. 278, 1823-1830, https://doi.org/10.1098/rspb.2010.1295 (2011).

17. Tewksbury, J. J., Huey, R. B. \& Deutsch, C. A. Putting the heat on tropical animals. Science 320, 1296-1297, https://doi.org/10.1126/ science.1159328 (2008).

18. Huey, R. B. et al. Why tropical forest lizards are vulnerable to climate warming. Proc. R. Soc. B Biol. Sci. 276, 1939-1948, https://doi. org/10.1098/rspb.2008.1957 (2009).

19. Diamond, S. E. et al. Who likes it hot? A global analysis of the climatic, ecological, and evolutionary determinants of warming tolerance in ants. Glob. Change Biol. 18, 448-456, https://doi.org/10.1111/j.1365-2486.2011.02542.x (2012).

20. Duarte, H. et al. Can amphibians take the heat? Vulnerability to climate warming in subtropical and temperate larval amphibian communities. Glob. Change Biol. 18, 412-421, https://doi.org/10.1111/j.1365-2486.2011.02518.x (2012).

21. Kingsolver, J. G., Diamond, S. E. \& Buckley, L. B. Heat stress and the fitness consequences of climate change for terrestrial ectotherms. Funct. Ecol. 27, 1415-1423, https://doi.org/10.1111/1365-2435.12145 (2013).

22. Hoffmann, A. A., Chown, S. L. \& Clusella-Trullas, S. Upper thermal limits in terrestrial ectotherms: how constrained are they? Funct Ecol. 27, 934-949, https://doi.org/10.1111/j.1365-2435.2012.02036.x (2013).

23. Diamond, S. E. \& Yilmaz, A. R. The role of tolerance variation in vulnerability forecasting of insects. Curr Opin Insect Sci. 29, 85-92, https://doi.org/10.1016/j.cois.2018.07.009 (2018).

24. MacLean, H.J. et al. Evolution and plasticity of thermal performance: an analysis of variation in thermal tolerance and fitness in 22 Drosophila species. Philosophical Transactions of the Royal Society of London. Series B, Biological Sciences. 374, https://doi. org/10.1098/rstb.2018.0548 (2019).

25. Pinsky, M. L., Eikeset, A. M., McCauley, D. J., Payne, J. L. \& Sunday, J. M. Greater vulnerability to warming of marine versus terrestrial ectotherms. Nature 569, 108-111, https://doi.org/10.1038/s41586-019-1132-4 (2019). 
26. Leather, S. R. et al. The ecology of insect overwintering. - Cambridge University Press (1995).

27. Buckley, L. B., Arakaki, A. J., Cannistra, A. F., Kharouba, H. M. \& Kingsolver, J. G. Insect development, thermal plasticity and fitness implications in changing, seasonal environments. Integr. Comp. Biol. 57, 988-998, https://doi.org/10.1093/icb/icx032 (2017).

28. Buckley, L. B., Ehrenberger, J. C. \& Angiletta, M. J. Jr Thermoregulatory behaviour limits local adaptation of thermal niches and confers sensitivity to climate change. Funct. Ecol. 29, 1038-1047, https://doi.org/10.1111/1365-2435.12406 (2015).

29. Nilsson-Örtman, V. \& Johansson, F. The Rate of Seasonal Changes in Temperature Alters Acclimation of Performance under Climate Change. Am. Nat. 190, 743-761, https://doi.org/10.1086/694412 (2017).

30. Vasseur, D. A. et al. Increased temperature variation poses a greater risk to species than climate warming. Proc. R. Soc. B Biol. Sci. 281, 20132612, https://doi.org/10.1098/rspb.2013.2612 (2014).

31. Marshall, K. E. \& Sinclair, B. J. The relative importance of number, duration and intensity of cold stress events in determining survival and energetics of an overwintering insect. Funct. Ecol. 29, 357-366, https://doi.org/10.1111/1365-2435.12328 (2015).

32. Visser, M. E. \& Both, C. Shifts in phenology due to global climate change: the need for a yardstick. Proc. R. Soc. B Biol. Sci. 272, 2561-2569, https://doi.org/10.1098/rspb.2005.3356 (2005).

33. van Heerwaarden, B., Malmberg, M. \& Sgro, C. M. Increases in the evolutionary potential of upper thermal limits under warmer temperatures in two rainforest Drosophila species. Evolution 70, 456-464, https://doi.org/10.1111/evo.12843 (2016).

34. Nilsson-Örtman, V., Stoks, R. \& Johansson, F. Competitive interactions modify the temperature dependence of damselfly growth rates. Ecology 95, 1394-1406, https://doi.org/10.1890/13-0875.1 (2014).

35. Dixon, A. F. G. et al. Relationship between the minimum and maximum temperature thresholds for development in insects. Funct. Ecol. 23, 257-264, https://doi.org/10.1111/j.1365-2435.2008.01489.x (2009).

36. Tauber, M. J. et al. Seasonal adaptations of insects. - Oxford University Press on Demand (1986).

37. Angilletta, M. J. Thermal adaptation: a theoretical and empirical synthesis. Oxford University Press, USA (2009).

38. Delworth, T. L. et al. GFDL's CM2 global coupled climate models. Part I: Formulation and simulation characteristics. J. Clim. 19, 643-674, https://doi.org/10.1175/JCLI3629.1 (2006).

39. Stearns, S. C. The evolution of life histories (1992).

40. Osborne, P. L. Tropical ecosystems and ecological concepts. - Cambridge University Press (2000).

41. Stillman, J. H. \& Somero, G. N. A comparative analysis of the upper thermal tolerance limits of eastern Pacific porcelain crabs, genus Petrolisthes: influences of latitude, vertical zonation, acclimation, and phylogeny. Physiol. Biochem. Zool. 73, 200-208, https://doi. org/10.1086/316738 (2000).

42. Diamond, S. E. et al. Climatic warming destabilizes forest ant communities. Sci. Adv. 2, e1600842, https://doi.org/10.1126/ sciadv.1600842 (2016).

\section{Acknowledgements}

We thank Lock Rowe for valuable comments on a previous version of this article. FJ was supported by the Swedish Research Council and GO was supported by a Spanish Ministry of Science, Innovation and Universities "Ramón y Cajal” grant RYC-2016-20656. Open access funding provided by Uppsala University.

\section{Author contributions}

F.J. conceived the study and wrote the first draft. F.J., G.O. and V.N.-Ö. contributed equally to data collection data analysis and writing.

\section{Competing interests}

The authors declare no competing interests.

\section{Additional information}

Supplementary information is available for this paper at https://doi.org/10.1038/s41598-020-65608-7.

Correspondence and requests for materials should be addressed to F.J.

Reprints and permissions information is available at www.nature.com/reprints.

Publisher's note Springer Nature remains neutral with regard to jurisdictional claims in published maps and institutional affiliations.

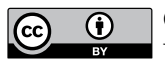

Open Access This article is licensed under a Creative Commons Attribution 4.0 International License, which permits use, sharing, adaptation, distribution and reproduction in any medium or format, as long as you give appropriate credit to the original author(s) and the source, provide a link to the Creative Commons license, and indicate if changes were made. The images or other third party material in this article are included in the article's Creative Commons license, unless indicated otherwise in a credit line to the material. If material is not included in the article's Creative Commons license and your intended use is not permitted by statutory regulation or exceeds the permitted use, you will need to obtain permission directly from the copyright holder. To view a copy of this license, visit http://creativecommons.org/licenses/by/4.0/.

(C) The Author(s) 2020 